\title{
Bioecology and Efficacy of Aenasius bambawalei in Population Management of Invasive Mealybug, Phenacoccus solenopsis on Cotton Crop in Pakistan
}

Ashfaque Ali Dhaunroo $^{1 *} \quad$ Tufail Ahmed Wagan $^{2} \quad$ Muhammad Mithal Jiskani $^{3} \quad$ Ghulam Hussain Abro 1. Department of Entomology, Faculty of Crop Protection, Sindh Agriculture University, Tandojam, Pakistan 2. Department of Plant Protection, Shaheed Zulfiqar Ali Bhutto Agricultural College, Dokri, Pakistan 3. Department of Plant Pathology, Faculty of Crop Protection, Sindh Agriculture University, Tandojam, Pakistan

\begin{abstract}
Biology and parasitization efficiency of Aenasius bambawalei Hayat (Hymenoptera: Encyrtidae) on mealybug, Phenacoccus solenopsis Tinsley were studied under laboratory condition. The rate of development of parasitoid varied on different life stages of mealybug. Total development time from oviposition to adult emergence was shortest on second instar followed by third instar and adult. Sex ratio of parasitoid also varied greatly on different life-stages.
\end{abstract}

Keywords: Cotton, Phenacoccus solenopsis, Aenasius bambawalei

DOI: $10.7176 /$ JNSR/9-10-04

Publication date:May $31^{\text {st }} 2019$

\section{Introduction}

Phenacoccus solenopsis Tinsley (Hemiptera: Pseudococcidae) is a highly polyphagous and invasive mealybug species attacking more than 200 plants comprising field and horticultural crops, ornamentals, medicinal plants and weeds (Afzal et al. 2009, Wang et al. 2010, Fand and Suroshe 2015). It infests the leaves, fruits, branches, main steams, trunks and roots feeding on phloem sap (Wang et al. 2010). Attacked shoots and leaves are malformed due to production of large amounts of honeydew which is responsible for the development of sooty mold (Gullan and Kosztarab 1997). Phenacoccus solenopsis could complete about 8 -12 generations in a year (Fand and Suroshe 2015). The outbreak of $P$. solenopsis on cotton and other plants in Pakistan was first recorded in 2005 (Wang et al. 2010). Later, mealybug outbreak was also recorded from India (Yousif et al. 2007). This devastating pest has spread throughout the cotton growing areas of Pakistan and has become most serious pest of cotton and many other important crops (Arif et al. 2009). Reportedly outbreaks of P. solenopsis on cotton caused 30-60\% yield losses in Pakistan and India during 2005-2009 (Fand and Suroshe 2015).

Phenacoccus solenopsisis is difficult to control with insecticides because it is protected with a hydrophobic waxy layer which serves as a barrier to penetration of insecticides (Afzal et al. 2009). There are many mealybug species causing serious damage to agriculture and horticulture crops such as Pseudococcus viburi, citrus mealybug, Planococcus citri (Rissol) and cassava mealybug, Phanacoccus herreni Cox and Williams which are successfully managed by introduction and release of parasitoids in different parts of world. Among many parasitoids, the Encyrtids are documented as potent parasitoids of mealybug species and play important role in biological control of several species (Bertschy et al. 2000, Karamaouna and Copland 2000, Dorn et al. 2001).

Before introduction and release of any potential parasitoid for population management of a pest insect, basic studies are required on host-parasitoid relationships in terms of suitable host size and stage for optimal biology and population growth of parasitoid and influence of host size on sex ratio of parasitoid species. Development of a parasitoid on suitable stage is an important consideration and is generally positively correlated with progeny fitness (Hagvar and Hofsvang 1991, King 1993). Female biased sex ratio with large body size and fast development of parasitoid are required for successful biological control program (Karamaouna and Copland 2000, Chong and Oetting 2006). Female body size of parasitoids is positively correlated with fitness parameters and dispersal ability (Harvey et al. 2001, Chong and Oetting 2006). Aenasius bambawalei Hayat (Hymenopter: Encyrtidae) is a new parasitoid species described in 2009 (Hayat 2009). This parasitoid was first time recorded in Indo-Pakistan in 2008 (Mahmood 2008). Aenasius bambawalei has been reported as an effective parasitoid of P. solenopsis in India (Gautam et al. 2009) and Pakistan (Mahmood et al. 2011, Solangi and Mahmood 2011). This is a newly discovered parasitoid species, information is lacking on its bioecology and prasitization efficiency under laboratory conditions (Ashfaque et al. 2010, Fand et al. 2011).

In the present investigation we studied the biology of $A$. bambawalei on different life stages of its host $P$. solenopsis. Influence of host stage on biological parameters of $A$. bambawalei such as days to parasitized mealybug mummy formation, adult emergence and their sex ratio. 


\section{Materials and Methods}

Mealybug

The culture of mealybug, $P$. solenopsis was established in the laboratory from individuals collected from cotton fields and maintained on potato sprouts (cv. Aladin). Potato sprouts were grown in $15 \mathrm{~cm}$ plastic pots placed in wooden cage $(30 \times 30 \times 45 \mathrm{cms})$. The cage has two sides made of glass panels and two sides of wire gauze. One side of cage had a circular hole $(15 \mathrm{~cm})$ covered with net for handling of insects. The laboratory temperature was maintained at $27 \pm 1{ }^{\circ} \mathrm{C}$ with $50-65 \% \mathrm{RH}$ and L16:D8 photoperiod. The parasitoid, A. bambawalei was reared on $P$. solenospsis feeding on potato sprouts in cages in the laboratory.

Biology of Aenasius bambawalei

Phenacoccus solenospsis were transferred from the mass culture on cotton (cv. NIAB-78) leaf. The leaf was kept with its lower surface upwards on a layer of potato dextrose agar in a plastic bottle $(10 \mathrm{~cm} \mathrm{dia,} 15 \mathrm{~cm} \mathrm{height)}$ covered with muslin cloth tied with rubber band. Four stages of $P$. solenospsis were used in the study, that is, first, second and third instars and female mealybugs. Freshly moulted insects were used in the experiments.

Mummified mealybugs were collected from the mass culture and put into transparent gelatin capsules (5.0 $\mathrm{mg}$ size $)$ and left in a ventilated plastic sandwich box $(20 \times 15 \times 10 \mathrm{~cm})$. They were checked twice per day at the same time for parasitoid emergence. Freshly emerged male and female parasitoids were paired together in a glass tube $(10 \times 2 \mathrm{~cm})$ for 24 hours to mate. Next day, after mating, both male and female parasitoids were transferred to plastic bottles containing mealybugs on cotton leaf for parasitization. A moist cotton swabs and $50 \%$ honey solution drops on paper strips were provided for parasitoid feeding and for maintaining moist conditions inside the bottle.

The different host sizes were offered separately at 100 mealybugs / bottle to the experimental wasps in no choice experiments. Mealybugs were transferred to fresh cotton leaf with fine paintbrush daily in a clean bottle to avoid contamination. Cotton swabs and paper strip with honey drops were also changed daily. Parasitoids were transferred in a glass tube $(8 \times 2 \mathrm{~cm})$ and released into the respective treatments for parasitization. The preliminary experiments on biology of $A$. bambawalei indicated that female wasps could lay eggs for 20-21 days. Therefore, fecundity and parasitization of females were observed up to 21 days. Data on parasitization were recorded on different days of parasitoid adult life and on cumulative basis. Each instar of $P$. solenospsis was exposed to $A$. bambawalei for 21 days in succeeding manner. As such, there were 21 pairs of $A$. bambawalei released for parasitization for a period ranging from one to twenty one days. Parasitoid pair one was released for one day, pair two for two days and so on up to 21 days. After stipulated period, parasitoids were discarded and mealybugs were retained for recording of parasitization. Mealybugs were then transferred from plastic bottle to Petri dish $(15 \mathrm{~cm}$ dia, $1 \mathrm{~cm}$ height) lined with moist filter paper. Whatman ${ }^{\circledR}$ No. 1 filter paper was provided with a fresh cotton leaf daily and mummies were observed twice a day. When mummies appeared, they were recorded and transferred to a gelatin capsule till adult emergence. This experiment was replicated four times.

Statistical analysis

The $P$. solenopsis infestation was compared using analysis of variance (ANOVA). The treatment means were compared at the $P=0.05$ significance level. Regression analyses were carried out between days of exposure of $P$. solenopsis and rate of parasitism of A. bambawale (Zar, 2010). All the statistical analyses were carried out on a computer using statistical software (STATISTIX ${ }^{\circledR}$ VERSION-8.1, Analytical Software, Inc. Tallahassee, FL., USA).

\section{Results}

Biology of A. bambawalei

The biology of endoparasitiod, Aenasius bambawalei was greatly influenced by host development stage. Development time to mummy formation was shortest when second instar $P$. solenopsis was offered as a host for parastitization, followed by third instar. The longest time to mummy formation (Mean $\pm \mathrm{SE}, 11.09 \pm 09$ days) was recorded on female adult $P$. solenopsis (Fig. 1). 


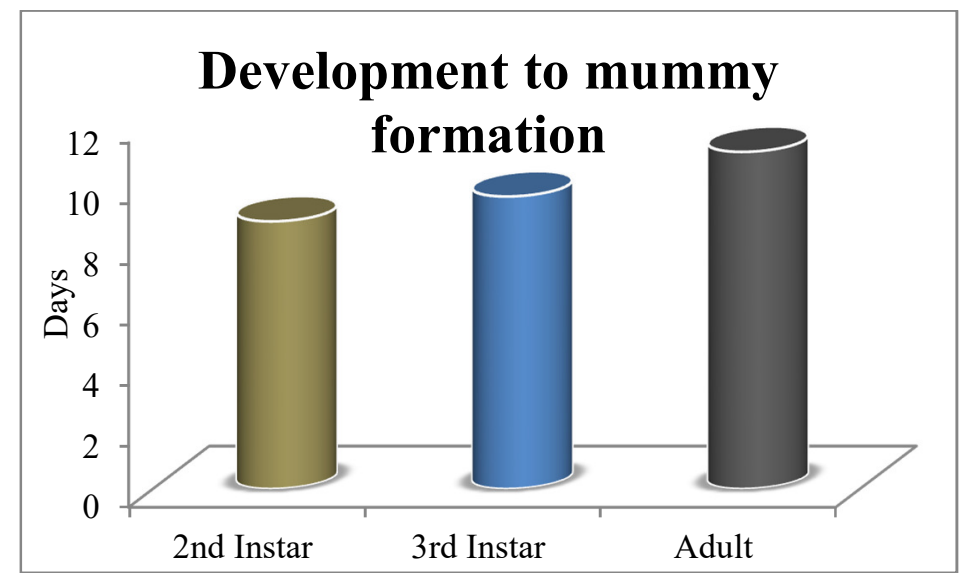

Fig.1. Development to mummy formation of P. solenopsis by the parasitism of A. bambawalei under laboratory conditions.

Majority of mummies were formed in 8 to 9 days, when second instar P. solenopsis was offered as a host. When third instar and female adult, $P$. solenopsis were offered as a host, duration of mummy formation was increased. More than 50\% of mummies were formed in 9 and 10, and 10 and 11 days, respectively when third instar and female adult stages were given for parasitizaton (Fig. 2). Duration of mummy (pupal) stage of $A$. bambawalei did not vary greatly due to parasitization of different host stages. The length of pupal period of $A$. bambawalei depended on the development stage of $P$. solenopsis. Pupal stage lasted from 3 to 7 days on different host stages of P.solenopsis (Fig. 3).

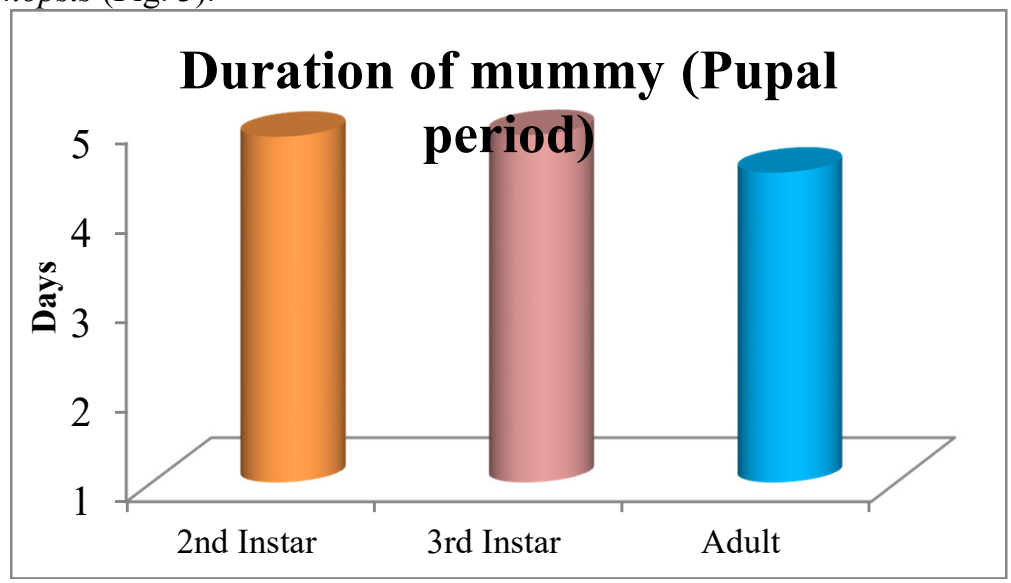

Fig.2. Duration of mummy of $P$. solenopsis by the parasitism of $A$. bambawalei under laboratory conditions.

Duration of mummy (pupal) stage of $A$. bambawalei was longest on third instar, $P$. solenopsis nymphs and the shortest on adult female. When second instar was offered as host $69.5 \%$ had completed their pupal period in 4 to 5 days. When $A$. bambawalei was released on third isntar $P$. solenopsis to parasitize, $76.8 \%$ completed their pupal stage in 4 to 5 days. A. bambawalei when offered adults of $P$. solenopsis as a host, 93.3\% had pupal period of 4 to 5 day. Total development time of $A$. bambawalei was also affected due to parasitizing on different life stages of $P$. solenopsis. Host development stage greatly affected the sex ratio of parasitoid. When feeding on second instar $P$. solenopsis, only male progeny was produced. When 3 instar and adult stages of host, $P$. solenopsis were offered for parasitization male and female biased sex ratios were observed, respectively. The highest range of parasitization was recorded on adult host stage compared with nymphal stages (Fig. 4). The life time cumulative and mean daily parasitization of $A$. bambawalei depended on the life stage of its host $P$. solenopsis. There was a significant correlation between days of exposure and rate of parasitism (Fig. 5). The average daily rate of parasitization of $A$. bambawalei on $P$. solenopsis was $2.27 \pm 0.66,3.33 \pm 0.74$ and $3.66 \pm 0.75($ mean $\pm \mathrm{SE})$ when second, third and adult female, respectively were offered to parasitoids. 


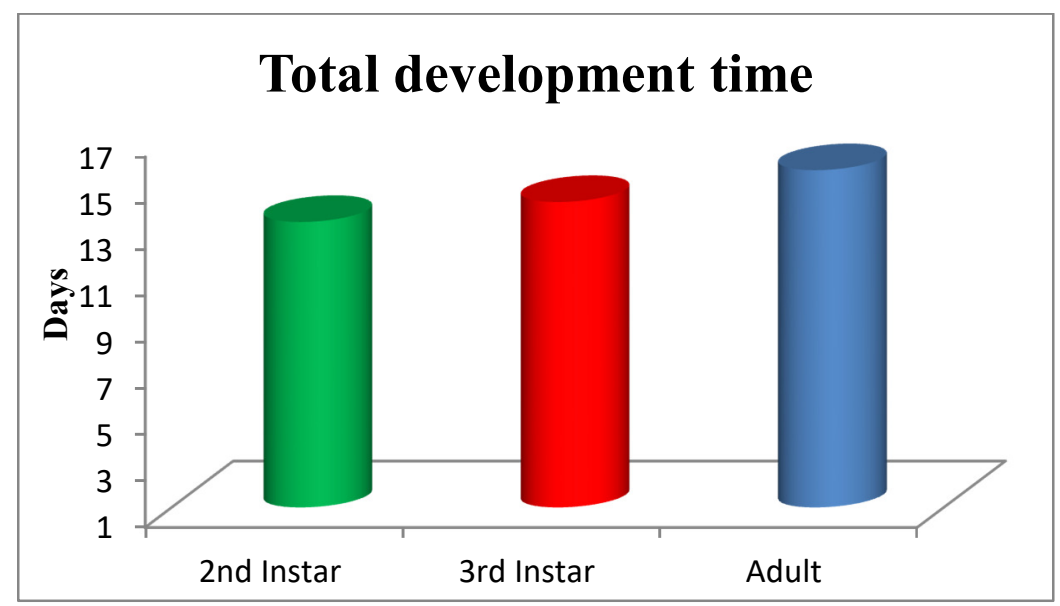

Fig.3. Total development time of $P$. solenopsis by the parasitism of $A$. bambawalei under laboratory conditions.

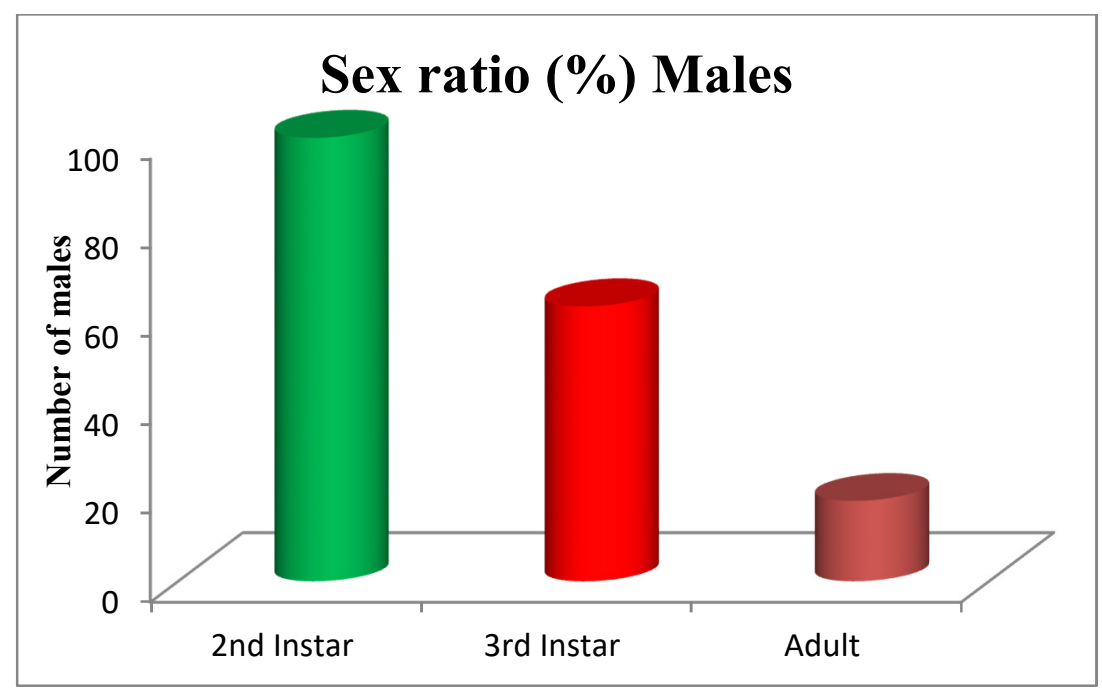

Fig.4. Sex ratio (\%) males of $P$. solenopsis by the parasitism of $A$. bambawalei under laboratory conditions.

\section{Discussion}

Development time of parasitoid, Aenasius bambawalei from oviposition to adult emergence varied on different life stages of its host, P. solenopsis and it was observed that younger the host, faster the development of parasitoid. Moreover, in each host instar males developed faster than females. Depending upon host size, parasitoids started their emergence from 12 days and continued for 18 days after ovipositions. Ashfaque et al. (2010) recorded adult emergence of Aenasius bambawalei from 11 to 13 days after oviposition. The difference in adult emergence might be due to temperature and host stages. They carried out their studies in May and June when the laboratory temparature was $28{ }^{\circ} \mathrm{C}$ and our studies were conducted in October and November when laboratory temperature was $27 \pm 1{ }^{\circ} \mathrm{C}$. When different host stages were offered to A. bambawalei for parasitization, it took longer time to develop on adult females compared with second and third instar nymphs. Ovipositing host females represent a depleting resource due to egg production, therefore, were less suitable for parasitoid development (de Jong and van Alphen 1989, Chong and Oetting 2006). No parasitization by A. bambawalei was observed on crawler stage (first instar nymphs) of $P$. solenopsis under no choice laboratory conditions. Under laboratory conditions, duration of second instar P. solenopsis, was 13 to 14 days and during first 10 days, of second nymphal instar, no parasitization was recorded. Parasitization was recorded in last four days of second nymphal instar; the emerging parasitoids were all male. Similar observations were recorded by Vijaya and Ram (2013). Many mealybug parasitoids of Encyrtidae showed preference for a range of host sizes and stages for parasitism (Chong and Oetting 2006). 


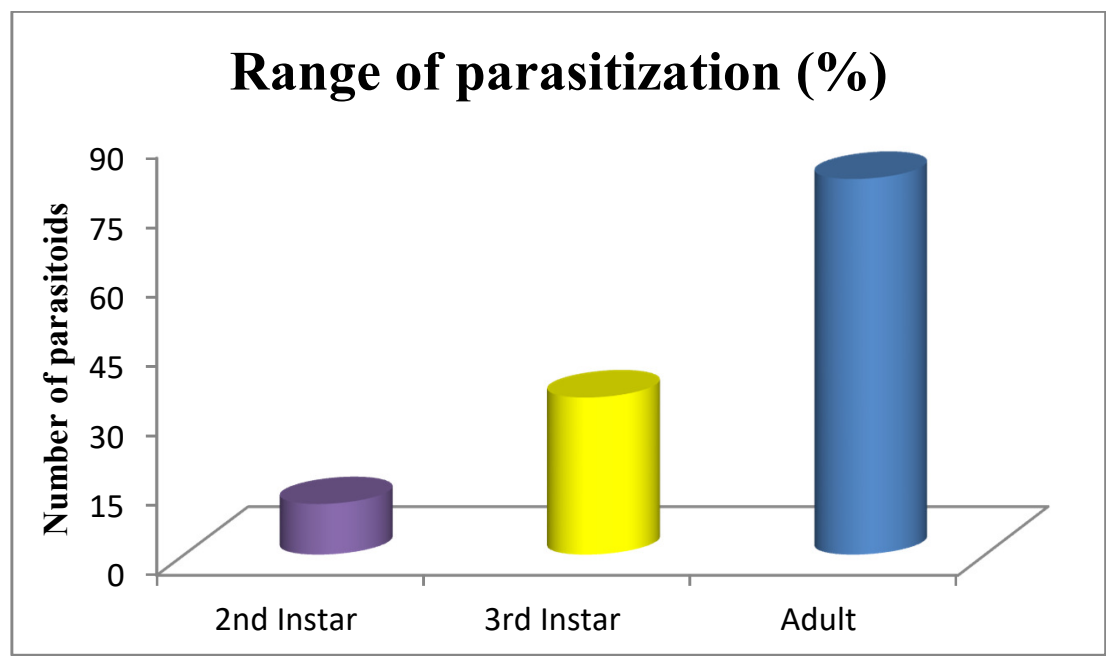

Fig.5. Range of parasitization (\%) of P. solenopsis by the parasitism of A. bambawalei under laboratory conditions.

Anagyrus mangicole Noyes attacked all developmental host stages but preferred the larger host stages over smaller ones (Bokonon-Ganta et al. 1995). While citrus mealybug parasitoid, Leptomastix dactylopii Howard, preferred the preoviposting adults and completely rejected the first and second instar nymphs for parasitism (de Jong and van Alphen 1989). Sex ratio of A. bambawalei was different on various life stages of host. Adult and third instar mealybugs produced more female parasitoids, while second instar produced more males. Adult and third instar mealybugs may be most suitable host size for parasitoid female to lay preferentially female eggs and second instar the less suitable (King 1993, Bertschy et al. 2000, Abdin et al. 2013). Male biased sex ratio of $A$. vexanswas found on second larval instar of cassava mealybug, P. herreni Cox and Williams (Bertschy et al. 2000), Leptomastidea abnormis parasitizing citrus mealybug, Planococcus citri (Cadee and van Alphen 1997), Leptomastidea apona (Walker) emerging from P. viburni (Signoret) (Karamaouna and Copland 2000) and $A$. bambawalei parasitizing P. solenopsis (Fand et al. 2011). Our studies showed that average female ovipositional period was $21 \pm 2$ days and it parasitized a mean of $81 \pm 0.95$ hosts in her life time. He et al. (2015) reported that female A. bambawalei ovipositional period was 21 days. Solongi and Mahmood (2011) reported that $A$. bambawalei females parasitized $80 \pm 4.67$ mealybugs in their life; Abdin et al (2012) reported a female $A$. bambawalei parasitoid parasitized 165 mealybugs in its entire life. Overall, results of our studies confirm the findings of other studies that $P$. solenopsis is an invasive and a very difficult pest to manage with a single strategy because of its biology and high reproductive potential. Aenasius bambawalei, although a very effective parasitoid of $P$. solenopsis and other predators active in cotton field could not bring pest population under control alone.

\section{References}

Abdin, Z., Hussain. F., Khan. M. A., Abbas S. K., Manzoor A., \& Shaina, H. (2013). Reproductive Fitness of Mealybug Parasitoid, Aenasius bambawalei Hayat (Hymenoptera: Encyrtidae).World Applied Sciences Journal, 26, 1198-1203.

Abdin, Z., Arif M. J., \& Gogi M. D. (2012). Biological characteristics and host stage preference of mealybug parasitoid, Aenasius bambawalei Hayat (Hymenoptera: Encyrtidae). Pakistan Entomologist, 34, 47-50.

Afzal, M, Rehman S. U, \& Siddiqui M. T. (2009). Appearance and management of a new devastating pest of cotton, Phenacoccus solenopsis Tinsley, in Pakistan. Beltwide Cotton Conferences, San Antonio, Texas, January 5-8, 2009. pp. 1023-1039.

Arif, M. I., Rafiq M., \& Ghaffar A. (2009). Host plants of cotton mealybug (Phenacoccus solenopsis): a new menace of cotton agroecosystem of Punjab, Pakistan. Int. Journal. Agriculture. Biological, 11, 163-167.

Ashfaque, M., Shah G. S., Noor A. R., Ansari S. P., \& Mansoor S. (2010). Report of a parasitic wasp (Hymenoptera: Encyrtidae) parasitizing cotton mealybug (Hemiptera: Pseudococcidae) in Pakistan and use of PCR for estimating parasitism levels. Biocontrol Sciences. \& Technology, 20, 625-630.

Bertschy, C., Turlings T. C. J., Bellotti A., Dorn S. (2000). Host Stage Preference and Sex Allocation in (Aenasius vexans), an Encyrtid Parasitoid the Cassava Mealybug. Entomologist. Exp. Apply, 95, 283-291.

Bokonon-Ganta, A. H., Neuenschwander P., van Alphen J. J. M., \& Vos M. (1995). Host stage selection and sex allocation by (Anagyrus mangicola), a parasitoid of the mango mealybug, Rastrococcus invadens (Homoptera: Pseudococcidae). Biological .Control, 5, 479-486.

Cadee, N., \& van Alphen J. J. M. (1997). Host Selection Preference and Sex Allocation in (Leptomastidea abnormisa) Parasitoid of the Citrus Mealybug Planococcus citri. Entomologist. Exp. Apply, 83, 277-284.

Chong, J. H., \& Oetting R. D. (2006). Functional response and progeny production of the Madeira mealybug 
parasitoid, (Anagyrus sp). the effects of host and parasitoid densities. Biological. Control, 39, 320-328.

Dorn, B., Mattiacci L., Anthony C., Bellotti A. C., \& Dorn. C. (2001). Host specificity and comparative foraging behavior of (Aenasius vexans \& Acerophagus coccois), two Endo-parasitoids of the cassava mealybug. Entomologist. Exp. Apply, 99, 331-339.

He, L. F., Feng D. D., Zhou P., Li, Z. S., \& Xu Z. F. (2015). Reproductive Modes and Daily Fecundity of Aenasius bambawalei (Hymenoptera:Encyrtidae), a Parasitoid of Phenacoccus solenopsis (Hemiptera: Pseudococcidae). Florida Entomologist, 98, 358-360.

Fand, B. B., Gautam R. D., \& Sachin S. S. (2011). Suitability of various stages of mealybug Phenacoccus solenopsis (Homoptera: Pseudococcidae) for development and survival of the solitary endoparasitoid Aenasius bambawalei (Hymenoptera: Encyrtidae). Biocontrol Sciences. Technology, 21, 51-55.

Fand, B. B. \& Suroshe S. S. (2015). The invasive mealybug, Phenacoccus solenopsis Tinsley, a threat to tropical and subtropical agricultural and horticultural production systems - A review. Crop Protection 69, 34-43.

Gautam, R. D., Suroshe, S. S., Saxena S. U., Fand B. B., \& Gupta T. (2009). Fortuitous biological control of exotic mealybug, (Phenacoccus solenopsis) -a boon for Indian growers. Annals of Plant. Protection. Sciences. 17, 473-474.

Gullan, P. J., \& Kosztarab M. (1997). Adaptation in scale insects Annuals Review of Entomology, 23-50.

Hagvar, E. B. \& Hofsvang, T. (1991). Aphid parasitoids (Hymenoptera: Aphidiidae): Biology, host selection and use in biological control. Biocontrol News Information, 12, 13-41.

Harvey, J. A., Harvey I. F. \& Thompson D. J. (2001). Life time reproductive success in the solitary endoparasitoid, (Venturiacanescens). Journal. Insect Behaviour. 14, 573-593.

Hayat, M. (2009). Description of a new species of Aenasius Walker (Hymenoptera: Encyrtidae), parasitoid of the mealybug, Phenacoccus solenopsis Tinsley (Homoptera: Pseudococcidae) in India. Biosystematica. 3, 21-26.

de Jong, P. W., \& van Alphen J. J. M. (1989). Host size selection and sex allocation in Leptomastix dactylopii, a parasitoid of Planococcus citri. Entomologist. Exp. Apply. 50, 161-169.

Karamaouna, F. \& Copland M. J. W. (2000). Host suitability, quality and host size preference of Leptomastix epona and Pseudaphycus flavidulus, two endoparasitoids of the mealybug, Pseudococcus viburni and host size effect on parasitoids sex ration and clutch size. Entomologist. Exp. Appl. 96, 149-158.

King, B.H. (1993). Sex Ratio Manipulation by Parasitoid Wasps, in: Evolution and Diversity of Sex Ratio in Insects and Mites, eds. D.L. Wrench and M.A. Ebbert, New York: Chapman and Hall, Pp. 418-441.

Mahmood, R. (2008). Break through in biological control of mealybug in Pakistan. Biocontrol News Information, 29, 38-39.

Mahmood, R., Aslam M. N., Solangi G. S., \& Samad A. (2011). Historical perspective and achievements in biological management of cotton mealybug, (Phenacoccus solenopsis) Tinsley in Pakistan. Proceedings of $5^{\text {th }}$ Asian Cotton Research and Development network, Conference held at Lahore, Pakistan, February, 23-25, 2011.

Solangi, G. S., \& Mahmood R. (2011). Biology, host specificity and population trends of Aenasius bambawalei Hayat and its role in controlling mealybug Phenacoccus solenopsis Tinsley at Tandojam Sindh. Proceeding of $5^{\text {th }}$ Asian Cotton Research and Development network, Conference held at Lahore, Pakistan, February. 23$25,2011$.

Vijaya \& Ram P. (2013). Effect of Host Stage on Parasitization and Biological Characteristics of Aenasius bambawalei Hayat (Hymenoptera: Encyrtidae), A Parasitoid of Phenacoccus solenopsis Tinsley. Journal of biological Control, 27, 126-129.

Wang, Y., Watson G. W., \& Zhang R. (2010). The potential distribution of an invasive mealybug Phenacoccus solenopsis and its threat to cotton in Asia. Agriculture \& Forest Entomology, 12, 403-416.

Yousif, M., Tayyib M., \& Shazia S. (2007). Mealybug problem on cotton in Pakistan.Pakistan Entomologist, 24, 49-50. 